\title{
ECE2014
}

\section{BIOCHEMICAL RESPONSE AND IMAGING CHANGES IN 99MTC-MIBI IN PATIENS WITH PRIMARY HYPERPARATHYROIDISM TREATED WITH CINACALCET}

Muñoz-Garach Araceli; Fernández-García Diego; Molina-Vega María; Sebastián Ochoa Arantzazu Martínez del Valle-Torres Mạ Dolores, Amrani-Raissouni Tomader, , Jiménez-Hoyuela García José Manuel, TinahonesMadueño Francisco-José.

Endocrinology and Nutrition with Nuclear Medicine Department. Virgen de la Victoria Universitary Hospital. Málaga. Spain

\section{INTRODUCTION}

Treatment with cinacalcet results in decreased uptake of radiopharmaceutical (because of decreased secretory activity of parathyroid glands as shown by previous studies in secondary hyperparathyroidism). This effect has not been studied in patients with primary hyperparathyroidism (PHPT).

OBJECTIVE Evaluate clinical and MIBI scintigraphy uptake changes of adenomas in patients treated with cinacalcet.

\section{PATIENTS \& METHODS}

$\square$ We collected data from patients between years 2009-2013. PTH.

$\square$ We evaluated demographic and analytical parameters. Scintigraphy changes (qualitatively and semiquantitatively) of 16 patients (4 patients have a negative one).

$\square$ We determined: uptake rate (\%) mean and maximum uptake images during early (15 minutes of contrast administration) and late (two hour) and reassessed after treatment with Cinacalcet, minimum period of three months.

\section{RESULTS}

$\square 27$ patients receive treatment with Cinacalcet, 10 men and 17 women, median diagnosis age 65 years.

$\square$ Initial profile: calcium $11.34 \pm 1.12 \mathrm{mg} / \mathrm{dl}$, phosphorus $2.62 \pm 0.38 \mathrm{mg} / \mathrm{dl}$ and PTH $260.96 \pm 190.04$ $\mathrm{i} \mathrm{pg} \mathrm{/} \mathrm{ml}$. Dose $30 \mathrm{mg}$ in $80 \%$ and $60 \mathrm{mg}$ in $20 \%$.

$\square$ We found significant decrease in calcium $(p<0.001)$ and PTH levels $(p<0.05)$. After treatment, calcium $9.62 \pm 1.19 \mathrm{mg} / \mathrm{dl}$, phosphorus $2.77 \pm 0.63 \mathrm{mg} / \mathrm{dl}$; PTH i $\pm 119.9179 .41 \mathrm{pg} / \mathrm{ml}$.

$\square$ One patient discontinue because of intolerance.

$\square$ Qualitative scale $75 \%$ of analyzed patients decreased uptake on the scan performed after treatment, $12 \%$ obtained same.

$\square$ One case negative in baseline scan then located adenoma in post-treatment scan.

$\square$ Quantitative scale shows a trend to statistical significance but no differences between pre and post assessments, maximum and mean or early and late phase uptake.

\begin{tabular}{|c|c|c|}
\hline & Median & $\begin{array}{c}\text { Standar } \\
\text { deviation }\end{array}$ \\
\hline Initial calcium (mg/dl) & 11,34 & 1,12 \\
\hline Mimp calcium (mg/dl) & 9,62 & 1,19 \\
\hline $\begin{array}{c}\text { Initial phosphorus (mg/ } \\
\text { dl) }\end{array}$ & 2,62 & 0,38 \\
\hline $\begin{array}{c}\text { Mimp phosphorus (mg/ } \\
\text { dl) }\end{array}$ & 2,77 & 0,63 \\
\hline Initial PTH i (pg/ml) & 260,96 & 190,04 \\
\hline Mimp PTH i (pg/ml) & 179,41 & 119,9 \\
\hline
\end{tabular}
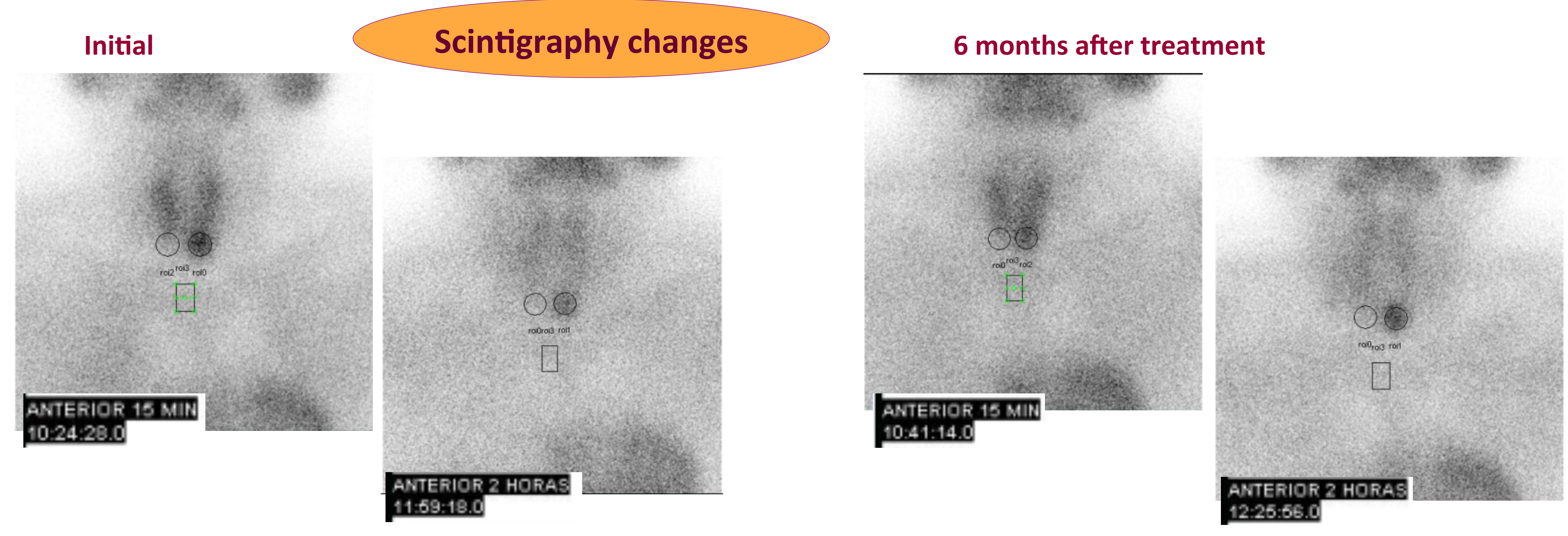

\section{CONCLUSIONS}

$\square$ Treatment with Cinacalcet is effective reducing calcium levels in PHPT patients.

$\square$ Cinacalcet seems to decrease scintigraphy uptake of parathyroid adenomas in patients with PHPT.

$\square$ Further studies should evaluate the clinical relevance of this finding. 